\title{
Pedro Henríquez Ureña y sus Presencias en Cuba
}

\begin{abstract}
$\mathbf{T}^{\mathrm{N}}$ el interesante trabajo "Hermano y Maestro", que preE cede la Antología de Pedro Henríquez Ureña, su hermano Max ofrece datos y fechas imprescindibles para mejor conocer los primeros pasos en las letras, como poeta y crítico, de quien llegara a ser ilustre humanista y animador de la cultura americana. Allí se nos presenta con precisión el que fue un caso de precocidad literaria, pues sus primeras composiciones poéticas corresponden a sus más tiernos años de edad. La inclinación a la crítica surge a poco, y según recuerda Max, uno de los primeros esbozos de Pedro fue un comentario en una velada infantil celebrada durante la estancia de la familia en Puerto Plata, sobre una "conocida composición poética de Gutiérrez Nájera, 'La Serenata de Schubert'”. El comentario y la crítica llegaron a ser frecuentes, especialmente en las reuniones de la casa de las hermanas Feltz, un centro de lecturas y de vida intelectual. En el ensayo, a manera de dedicatoria, que figura en su libro Horas de Estudio, "A Leonor M. Feltz, en Santo Domingo", el autor dejó registrado ese feliz período de su adolescencia:
\end{abstract}

¿Qué multitud de libros recorrimos durante el año en que concurri a vuestra casa, y, sobre todo, qué rio de comentarios fluyó entonces! Vuestro gusto, sin olvidar el respeto debido a los clásicos, a Shakespeare (que entonces releíamos casi entero), a los maestros españoles, nos guió a recorrer la poesía castellana de ambos mundos, el teatro español desde los orígenes del romanticismo, la novela francesa, la obra de Tolstoi, la de 
D'Annunzio, los dramas de Hauptmann y de Sudermann, la literatura escandinava reciente y, en especial, el teatro de Ibsen, cuyo apasionado culto fue el alma de vuestras reuniones.

Esta página, escrita en México en octubre de 1909, es como el resumen de un momento culminante de su formación, aquel en que el ensayista y el humanista se revelan y emprenden el camino de su futura dedicación.

Los vaivenes políticos y revolucionarios juegan papel importante en la vida familiar. En 1901, cuando Pedro sólo tenía 17 años de edad, su padre lo envía a New York, junto con su hermano mayor Fran, para que cursara estudios universitarios. Pero al año siguiente ambos tienen que trabajar como empleados de comercio, pues la revolución de 1902 derriba al gobierno, obliga al padre a trasladarse a Cuba y finalmente se establece como médico en Santiago, donde en 1904 se le junta Max. En ese mismo año Pedro y Fran se trasladan a La Habana, y aquí, por recomendación del generalísimo Máximo Gómez, dominicano de nacimiento, obtienen empleo en una casa de comercio.

Pedro y Max, en sus tempranos años de Santo Domingo, sintieron la obsesión de los periódicos literarios. Y manuscritas aparecieron sus primeras hojas, dedicadas a ser leídas en el círculo familiar. Max fundó $L a$ Tarde, que cambió después por El Faro Literario. Y más tarde fundó El Ideal, revista literaria que imprimía con otros compañeros. Pedro "echó a la circulación otra hojita, también hebdomadaria, que bautizó La Patria, y en ella aparecieron reproducciones de nuestros poetas con comentarios suyos, que acaso fueran la primera manifestación de sus futuras dotes de crítico y ensayista". Fran, por su parte, aparecía dirigiendo El Ibis. Esa inclinación resurgió cuando Max vino a residir con su padre en Santiago de Cuba, al fundar y dirigir Cuba Literaria, revista de la cual, según nos dice, a más de colaborador, Pedro era, en realidad, codirector. En ella aparecieron sus primeros trabajos publicados en Cuba, los que, según afirma su hermano Max, mejor lo dieron a conocer como crítico y ensayista, entre ellos los estudios sobre Rodó y D'Annunzio. 
No se conoce con exactitud la fecha en que Pedro Henríquez Ureña llegó a Cuba en el año 1904, pero debió ser en los meses finales. Los artículos "D'Annunzio el poeta" y "Ariel", que Max publicó en Cuba Literaria, tienen las fechas 1903 y 1904, respectivamente, y seguramente fueron escritos antes de su llegada, así los dedicados a "Bernard Shaw", "Richard Strauss y sus poemas tonales" y "La ópera italiana", que figuran en su primer libro Ensayos críticos, publicado en La Habana a fines de 1905. En el trabajo sobre Bernard Shaw, una cita de Varona hace suponer que el trabajo pudo haberse escrito en La Habana. Todos los demás que integran el libro llevan la fecha de 1905, y aunque el autor hubiera utilizado para su redacción borradores traídos de Santo Domingo y Nueva York, con seguridad la forma última en que los publicó, fue aquí donde se la impuso. Y uno de los artículos, "El modernismo en la poesía cubana", fue concebido y escrito en contacto directo con nuestro medio literario.

Ensayos críticos contiene, en germen, muchas de las direcciones de la dedicación literaria del maestro. Su inclinación a la literatura inglesa está presente en sus tres ensayos sobre Oscar Wilde, Arthur Wing Pinero y Bernard Shaw; el crítico literario aparece en sus artículos sobre Rubén Darío, Rodó, José Joaquín Pérez, D’Annunzio y el trabajo sobre el modernismo en nuestra poesía. También apunta su interés por el pensamiento en América, al estudiar las aportaciones a la Sociología del dominicano Hostos y del cubano Enrique Lluria, y su afición a los temas musicales.

$\mathrm{Su}$ penetración en muchos de esos estudios le lleva a adelantarse en sus juicios no sólo a otros críticos de nuestra América, sino de la misma Francia. Así podemos leer hoy, cincuenta años después de haber sido escrito, su opinión sobre Bernard Shaw, sorprendiéndonos su claridad de visión y de juicio:

Bernard Shaw es quizás la más curiosa proyección del espiritu céltico sobre las letras anglosajonas. Como humorista, pertenece por entero al mundo inglés y sólo dentro de éste se le apreciará plenamente; como pensador, se ha adelantado a su público y le ha asombrado con sus extravagancias de fumista literario, que contrastan con la seriedad de su carácter y de su 
vida privada. Paradoja viviente, se le llama: un devoto de Schopenhauer y de Nietzsche que, en el caso, se desprendería de su último centavo para dar de comer al hambriento.

Dos de sus trabajos de esta época, los consagrados a Darío y a Rodó, nos sirven también para apuntar su sagacidad crítica, pues además de ser trabajos de los veinte años, tanto la obra de Darío como la de Rodó aun eran poco conocidas cuando tales artículos se escribieron. La carta que Rodó le dirigió al recibir el volumen, fechada en 20 de febrero de 1906, adelanta juicio de mucha estimación sobre sus disposiciones intelectuales:

Agradézcole su libro y su juicio porque revelan un espíritu levantado sobre el nivel de la mediocridad, y porque veo en Ud. un verdadero escritor, una hermosa promesa para nuestra crítica americana, $\tan$ necesitada de sangre nueva que la reanime. Me agradan mucho las cualidades de espíritu que Ud. manifiesta en cada una de las páginas de su obra, y que son las menos comunes, y las más oportunas y fecundas, con relación al carácter de nuestra literatura. Me agradan la solidez y ecuanimidad de su criterio, la reflexiva seriedad que da el tono de su pensamiento, lo concienzudo de sus análisis y juicios, la limpidez y precisión de su estilo. Me encanta esa rara y felicísima unión del entusiasmo y la moderación reflexiva que se da en Ud. como en pocos. Y me complace reconocer, entre su espíritu y el mío, más de una íntima afinidad y más de una estrecha simpatía de ideas.

Ensayos críticos tuvo excelente acogida, y fue el mensaje de ese libro el que dio a conocer al autor ventajosamente en América. Pero no fue sólo esa publicación la que dejó huella imborrable de este primer paso del escritor por nuestra tierra. Su hermano Max, que, como ya vimos, había fundado en Santiago de Cuba la revista Cuba Literaria, suspendió su publicación y vino a residir a la Capital, entrando a formar parte de la redacción del periódico La Discusión y del semanario $E l$ Fígaro. Juntos pasaron algunos meses en La Habana en ese año de 1905, y El Fígaro saludó la presencia de Max en su número de 5 de marzo, en nota al pie de su retrato. En cuanto a Pedro, sus colaboraciones en La Discusión fueron varias: "Los dramas de Pinero", "Tendencias de la poesía cubana", "Martí escritor", entre las que hemos hallado en ese año de 1905. 
Siguiendo el itinerario marcado por Max, sabemos que no duró mucho la estancia de Pedro en Cuba, pues había decidido emprender viaje a México, para donde embarcó a principios de 1906. En total, poco más de un año de duración tuvo esta permanencia, pero dejó impresión señalada en su vida de escritor. No sólo aquí publicó su primer libro, sino que tomó el rumbo de México, donde tendría reservado una altísima misión: la de contribuir de modo poderoso a la formación de una nueva conciencia literaria, artística y cultural, y a preparar el terreno para los cambios que ya los tiempos hacían presentir. Alfonso Reyes, testigo de mayor excepción, pudo decir, en la evocación que escribió al tener noticia de su muerte:

Pedro, el apostólico Pedro, representa en nuestra época, con títulos indiscutibles, aquellas misiones de redención por la cultura y la armonía entre los espíritus, que en Europa se cobijan bajo el nombre de Erasmo, y en América bajo el de ese gran civilizador, peregrino del justo saber y el justo pensar, que fue Andrés Bello.

$Y$ al reclamar como propio el derecho de llorarlo, termina así su evocación:

Aquí fundó su hogar. Y al cabo, nos ayudó a entender y, por mucho, a descubrir a México. Nuestro país era siempre el plano de fondo de su paisaje vital, la alusión secreta y constante de todas sus meditaciones. México fue para él la tierra firme en que asentó su vida y su campo de observación y de batalla por los ideales de América. Y para México fue, como lo llamó con acierto Daniel Cosío Villegas, "el hermano definidor".

Si su primera estancia en Cuba se señaló con la publicación de su primer libro, la primera de México, que comprendió casi seis años, se coronó con una obra allí compuesta en su totalidad, y que apareció publicada en París en las ediciones de la casa Ollendorff, en 1910. La gran labor que en esa primera década del siglo le tocó realizar, en un momento en que fermentaban los nuevos impulsos y existía como una fiebre en la juventud que buscaba afanosamente un camino que ya presentía, -cuando surgían los nombres que después habrían 
de ser gloriosos de Antonio Caso, José Vasconcelos, Alfonso Reyes, y algunos más-, Pedro Henríquez Ureña, con ser de edad semejante a la de sus compañeros, se les había adelantado con aquella precocidad sorprendente que siempre se le reconoció. Y así fue en buena medida el guiador, el consejero, el mentor de aquel grupo.

Su participación en todos los empeños juveniles que dieron al movimiento renovador de México el altísimo sentido e impulso que en buena parte fue un anticipo de la revolución mexicana, serán objeto de merecido estudio en este número. Sólo vamos a señalar ahora, por la resonancia que tuvo en Cuba, el encargo honroso de que fue objeto por parte del gobierno de México, el que al aproximarse la oportunidad del Centenario de su Independencia - 15 de septiembre de 1910resolvió publicar una Antología de Poetas Mexicanos, y para realizar tal empeño designó al poeta Luis G. Urbina "y al joven y ya ilustre crítico dominicano Pedro Henríquez Ureña, residente en México desde hace algunos años", como rezaba la nota que El Fígaro de La Habana insertó en su edición de 9 de enero de 1910, ilustrada con una "máscara" que firmaba Alberto Garduño.

Horas de estudio fue su consagración, no sólo en América sino aun en España. Y lo confirma la carta que en 23 de noviembre del mismo año en que dicha obra apareció, hubo de dirigir al joven maestro el eminente crítico y literato don Marcelino Menéndez y Pelayo, y que El Figaro de La Habana tuvo el privilegio de publicar poco después, en su número correspondiente al primero de enero de 1911. Es de suponer que esa carta, el reconocimiento más rotundo de una "exquisita educación intelectual comenzada desde la infancia y robustecida con el trato de los mejores libros", la dio a conocer el propio Pedro, enviándola desde México, como un anticipo de su próxima visita. Pero lo cierto es que se encontraba en La Habana a principios de ese año, y pudo asistir a la conferencia que en el Ateneo pronunció Enrique José Varona y que le da oportunidad para su comentario "Oyendo a Varona", que 
El Fígaro publicará en su número de 10 de abril. Aquella conferencia fue la que pronunció Varona tratando de su escepticismo, y de seguro impresionó vivamente al joven maestro que ya pudo señalar la índole de la incredulidad a que Varonz. se inclinaba, no por cierto de la índole sustancial, sino más bien intelectual, y no extrema, sino atemperada. Concluyó esclareciendo el punto en que Varona se situaba, refiriéndose a su posible contacto con el pragmatismo de William James, y concluyendo que el propósito respecto a esa conferencia debió ser darnos, no su "discurso del método", sino una lección de fe; con lo cual anticipó en más de treinta años su pensamiento sobre el "Maestro de Cuba".

Semanas después se publicó en la propia revista un artículo de Jesús Castellanos, iniciado con un saludo a su paso por nuestra capital, "con rumbo a su patria que hace algunos años abandonó", pero que es un análisis de la obra que sólo en pocos meses le ha precedido, y que Castellanos considera como un aporte de valor sobresaliente, ejercicio de la crítica, con sentido creador, al decir: "Pedro Henríquez Ureña es uno de los muy contados críticos que en la América trabajan, tomando la crítica en su sentido europeo de la más ardua cumbre literaria". Y la frase con que cerraba sus impresiones anticipaba lo que sería su camino: "He aquí una inteligencia que llega rápidamente a su climax de madurez. Su proceso de desenvolvimiento, revelador de nuevas vistas en el futuro americano, es una buena lección para ser contada al oído de nuestros jóvenes conquistadores".

De ese fugaz paso poco más quedó, pero ya los dos articulos que reseñamos bastan para revelar cómo era apreciado entre nosotros, $\mathrm{y}$ se le supo admirar y comprender desde su misma juventud.

La tercera estancia la consideramos la de mayor importancia, por la repercusión que tuvo en el ambiente cultural, y sobre todo porque le dio oportunidad de poner en práctica la que era ya su norma de alentador de vocaciones, como había ocurrido antes en México.

Breve había sido su estada en Cuba en el año 1911, desde donde se dirigió a Santo Domingo para permanecer allí poco más de un mes, pues llegado el 16 de mayo, regresó a México, 
vía Cuba, el 22 de junio de 1911. Allí permanece por tres años. Pero en abril de 1914 se encuentra otra vez entre nosotros. Su permanencia va a ser sólo de meses, pues ya en diciembre del mismo año se halla en Washington, desde donde envió numerosas correspondencias al Heraldo de Cuba, que lo había nombrado su representante especial. IMuchos de sus artículos aparecieron con su firma, pero también algunos con el pseudónimo $P$. Garduño. Y durante el año 1915 aun continuaron apareciendo crónicas suyas.

A la vez que sus artículos se publicaban en Heraldo de Cuba, no dejaba de colaborar en El Fígaro, y en la revista Cuba Contemporánea, de gran radio en toda nuestra América, y en la que ya en 1913 había aparecido su trabajo "Romances en América". Hallándose en La Habana se publicó en esta revista su estudio "El Maestro Hernán Pérez de Oliva", y se reimprimió en la Revista de la Facultad de Letras y Ciencias su conferencia sobre "Juan Ruiz de Alarcón".

De este período se menciona su "polémica" con Enrique José Varona. En realidad, no hubo verdadera polémica. Varona acababa de pronunciar su discurso sobre Gertrudis Gómez de Avellaneda, en el cual Henríquez Ureña encuentra una parte admirable, que le merece cálidos elogios, la que considera un estudio psicológico de la poetisa, "que hubiera sido magistral y acaso definitivo - dice-, si no se cortara y suspendiera brusca e inesperadamente, para ceder el paso a una segunda parte, de crítica tan estéril como interesante la otra". Y en la manera respetuosa y comedida en que la admiración que profesaba a Varona, y su propio temperamento exigían, hace la defensa de la lírica española, que el maestro cubano desconoció o trató con indiferencia, en frases para las que no hallaba justificación, precisamente por tratarse de quien nunca pecaba de ligero. "Los poetas españoles de los siglos de oro son grandes poetas líricos, y más aún, los mayores de nuestro idioma". Y complementa su apreciación agregando: "Hay momentos en la historia intelectual de España, en que el más alto pensamiento se refugia en los místicos y en los líricos. La poesía de las ideas, la "emoción intelectual", rara flor de cultura, se encuentra a menudo en ellos". En carta de 18 de mayo de 1914, que El Fígaro publica, Varona, apreciando el tono de deferen- 
cia, "la apreciación tan lisonjera de lo que aparezco a sus ojos", tiene la condescendencia de explanar los juicios en que disentían, y termina rogándole que admita, en cuanto le sea posible, sus descargos. $\mathrm{Y}$ así quedó precisado que sus puntos de vista no coincidían en algún extremo, pero Varona los sostenía con plena conciencia de su juicio, y sentaba una vez más su sentido relativista de la historia: "Las manifestaciones del arte son muy varias. Cada época tiende a tener las suyas preferidas. No se agravia a una época, cuando se reconoce la excelencia de otra. Y mucho menos cuando se reconoce que ésta excede a aquélla en tal o cual forma artística".

Vi entonces por primera vez a Pedro Henríquez Ureña. No recuerdo las circunstancias, pero sí el lugar. Trabajaba yo en la oficina de un notable abogado de La Habana, y era allí, además de empleado, amigo bien recibido y estimado en el círculo familiar. Entre el hijo mayor y yo, había nacido una cordial amistad. En los ratos desocupados conversábamos largamente de nuestros coincidentes intereses literarios. Nos transmitíamos nuestras impresiones de las últimas lecturas. Muchas mañanas, al llegar a mi mesa de trabajo, lo primero que hallaba en ella era una nota escrita en tono de comunicativo entusiasmo, en que Francisco José Castellanos me transmitía un juicio apresurado, pero vivo y certero, del libro que se había leído aquella misma noche, o me comunicaba algún proyecto de vida en que siempre había un ancho margen para las cosas del espíritu. Por las tardes, concluídas las labores, o en las horas del mediodía, teníamos nueva oportunidad de conversar, cuando no se sentaba al piano e interpretaba de modo personalísimo alguna de sus piezas predilectas. Uno de aquellos días tuve la primera noticia acerca de Pedro Henríquez Ureña, recién llegado a La Habana, noticia que, - he de confesarlo - era para mí la primera acerca de su existencia.

Francisco José me transmitía sus impresiones: era un ser dotado de extraordinario poder de penetración, que además tenía un don asombroso de conversación, e inagotable su sabi- 
duría en letras, en arte y aun en filosofía. Era una sorpresa un ser así, lleno de cordial interés por el sentir y el saber de los demás, que incansablemente gustaba de sondear en las almas y trataba de darles orientación adecuada y firme en el contacto con las letras. Lejos del diletantismo sin normas, y de la inconsistencia ambiente, tomaba en plano de absoluta seriedad los dominios de la inteligencia. Era una serena actividad de maestro, y se veía cómo su vida era un fluir esencial de derroteros y de acentuación de seguras normas creadoras.

En Francisco José Castellanos, en Mariano Brull, en José María Chacón y Calvo, en Luis A. Baralt, hallaba la promesa de verdaderos temperamentos literarios, y su misión tenía campo propicio en que ahondar. Día a día se iban sucediendo los coloquios, que a veces se alargaban de tal modo, que la noche transcurría en la conversación, que no terminaba sino con el alborear del nuevo día. Los ecos de estos nuevos diálogos platónicos me llegaban a través de la admirativa palabra de Francisco José, despertando mi creciente curiosidad e interés. Un día, al fin, pude escucharle largamente. La conversación se desenvolvió alrededor de una novela que leía en ese momento: Madame Bovary. El quiso conocer la razón de cada una de mis apreciaciones sobre la obra, pues no se contentaba con el juicio simple y de conjunto o con el entusiasmo que no pudiera razonarse. No puedo recordar las indicaciones que me hizo, pero desde luego se refirió a la necesidad de leer los libros directamente en el idioma en que se habían escrito y en ese caso concreto habló sobre el estilo de Flaubert. Algunas veces más tuve oportunidad de oírle. Pero nuestra amistad verdadera se forjó después, cuando él ya se había marchado y yo comencé a publicar algunos pequeños ensayos en periódicos y revistas. Se encontraba de profesor en la Universidad de Minnesota, en 1916, cuando Francisco José me mostró alborozado una carta que acababa de recibir. Había un párrafo consagrado a la impresión que le había producido la lectura de alguno de mis trabajos, y a vuelta de elogios generosos en extremo, y de lamentarse de no haberme consagrado más atención, surgía fórmulas para hallarme modo de vivir con suficiente independencia, y él mismo adelantaba ya la manera de que pudiera enseñar español en alguna universidad americana. Alentado 
por palabras venidas de pluma de tanta calidad, continué escribiendo y publicando artículos que siempre le mandaba. Ya sus cartas tenían de continuo una referencia a mis trabajos, señalándome pautas y dándome nuevos alientos. Recibía también los artículos de Chacón, y alguna vez, refiriéndose concretamente a esos ensayos nuestros, escribió estas palabras: "me hacen pensar que se puede reanudar en Cuba la tradición de escribir bien y seriamente".

En diciembre de 1917 , de regreso de un rápido viaje a Europa, recibí una larga carta que en cierto modo anudó el lazo de amistad que nos unía, forjado a través de mi devoción y de su generosa tolerancia. Comenzaba refiriéndose a un reproche imaginario, un reproche que presumía que podía haberle hecho, y extremó sus explicaciones. Vale la pena recoger ahora algunas palabras de aquella carta:

Yo creo - decía- en las cosas intelectuales, y en la seriedad de la dedicación (o aun, si quiere usted, profesión) literaria; pero sé lo que cuestan. Se sufre demasiado con ellas; se quiere hacer siempre más de lo que se puede (aunque se sea Goethe o Leonardo) y siempre se fracasa, como en todo. Si a nuestra devoción intelectual, acompañada siempre del sentido de nuestra impotencia, se le unen causas externas deprimentes, el caso es aun más grave. Así he llegado a la norma de que, en países como los nuestros, donde la lucha económica es tan desagradable, hay que resolverla antes que nada, y sólo dos clases de personas deben dedicarse a cosas intelectuales: las que tienen dinero o al menos holgura económica; y las que tienen "vocación", ya que a éstas nadie puede detenerlas $y$ en cambio su intenso amor a las cosas del espíritu les compensa de las molestias inevitables.

\section{La explicación venía después:}

Cuando pasé aquellos meses de 1914 en Cuba se me habló no poco de usted, y supe, no sólo su "afición" intelectual, sino también su situación en la vida, que le obligaba a tomar en serio la cuestión económica. Ante estos datos dije resueltamente a Francisco José: es mejor desalentarle, es mejor que dedique todas sus energías a la vida práctica, y se abra paso en ella; su "afición" intelectual nunca estará de más, pero no pretendamos que la convierta en "profesión", porque le traerá sinsabores que pueden evitársele. 
Finalmente, la consecuencia era la más lisonjera referencia a mi "vocación", y le hacía decir con verdadero humorismo: "y ha triunfado de todas las oposiciones, como en las "biografías de niños célebres".

Sus consejos me alentaron desde entonces continuamente, y su tesón fue superior a mis propias disposiciones. Por él me fue dado obtener en la Universidad de Princeton un cargo para enseñar español, que aunque desempeñé con apreciable fortuna, no supe aprovechar debidamente, como su reiterado consejo me indicaba. Entresaco de sus cartas algunos párrafos que permiten apreciar su decidido empeño en guiar mis pasos:

Acabo de recibir su carta y le contestó en seguida para decirle que ES INDISPENSABLE QUE CONTESTE USTED QUE SI, ( y esto lo escribía todo con mayúsculas). Diga usted que sí, y si ocurren otros contratiempos, siempre habrá tiempo para decir no, gran principio mexicano que yo no he sabido aplicar, pero euya grande utilidad he visto clara en estos días.

Y abundaba en otras razones convincentes:

Es absurdo que se vaya usted a quedar en Cuba, en la situación más o menos precaria en que vive. En Cuba, si no logra usted entrar en la diplomacia, y con las dificultades que encuentra para sus estudios, me temo que se vería obligado a vivir en empleos mezquinos, sin independencia y sin tiempo para el trabajo intelectual.

$\mathrm{Y}$ no contento con argumentos de esta fuerza, se entretiene mientras da "una fastidiosa clase de idioma" en su cátedra de Minnesota, en numerar mis objeciones, refutando una por una las siete que según él le había puesto para apoyar mi indecisión.

Y para no dejar lugar a dudas, terminaba así su carta:

Quizás le escriba a Marden indicándole la aceptación de usted aun antes de recibirla, pues cuento con ella.

Hemos abusado de la cita para que pueda apreciarse el interés que ponía al servicio de quienes él consideraba que debían y podían trabajar en serio por su superación intelectual. El caso seguramente no será único, y sin duda en muchos 
otros los resultados fueron infinitamente superiores. Pero se ve bien en éste la generosidad sin límites. Y todo porque él creyó que había una posibilidad literaria que debía salvarse.

Estando en los trámites de mi viaje a Princeton surgió lo inesperado. Un antiguo alumno de aquella Universidad, establecido en La Habana, había sido comisionado para visitarme y transmitir sus impresiones al profesor Marden, jefe del departamento de español. Tan pronto Henríquez Ureña tuvo la noticia me escribió poniéndome sobre aviso, temiendo que la entrevista, de no llevarse a cabo en la forma adecuada, pudiera traer dificultades. Y entre sus advertencias destaco ésta : "En primer lugar, no sea usted modesto. Con los norteamericanos no tiene éxito el sistema latino de rebajar el propio valer: ellos toman al pie de la letra lo que se les dice. Declare usted con absoluta franqueza lo que es"; y abundaba en apreciaciones sobre mi propia labor.

En sus cartas, hallaba siempre la lección de la amistad y del saber. Cuando le oponía mi falta de preparación para desistir de aceptar el ofrecimiento de Princeton, él me argüía: "No se preocupe usted por la 'falta de preparación'. Nunca se acaba de estudiar; pero si se está bien orientado, ya es bastante. Alcanazada la buena orientación no hay más sino seguir por ella, sin apresurarse demasiado". Y me of recía un programa de trabajo formado a través de su propia experiencia y de sus más caros anhelos:

Conviene ir leyendo a la vez lo muy nuevo, lo que tiene vida actual, y lo eterno; sin preocuparse mucho por conocer todas las figuras secundarias, pero procurando enterarse, por lo pronto, de la historia literaria y filosófica. No quiera escribir mucha crítica: la crítica es un veneno de que yo hago esfuerzos por librarme. Escriba ensayos, a la inglesa o a la española, como lo está usted haciendo. Aténgase de preferencia, como usted dice, a "las líneas generales y eternas".

Abundaban las noticias y opiniones sobre sucesos y personas, siempre en relación con las letras. Pero por momentos iba creciendo el trabajo que le cercaba y las excusas por no escribir aumentaban día a día: "Dos palabras. El tiempo no da para más", es el comienzo de una. Otra se inicia así: "No quiero repetir mis viejas excusas sobre mi "no escribir". 
A fines de septiembre de 1919 llegábamos a Princeton, pero él no había podido realizar su promesa de acompañarme durante los primeros días. Había emprendido un viaje por distintas ciudades - Chicago, Washington, New York-, de donde embarcó para Europa. De todas partes me llegaban sus palabras guiadoras. "Dedíquese a dar sus clases, al inglés y al francés, y verá que pronto se siente encarrilado, y resueltos sus problemas. Dentro de una semana se asombrará usted de que todo comience a parecerle más fácil". Era la constante voz animadora que me señalaba el camino, no siempre escuchada y seguida con la precisión que él apuntaba. $\mathrm{Y}$ cuando le llegaron mis explicaciones, seguramente confusas e inadmisibles, recibí a vuelta de correo el nuevo aliento: "No se deje dominar por el pesimismo". De Madrid, de Florencia, de Venecia, me siguieron llegando sus mensajes. Ahora, ya de regreso en New York y camino nuevamente de su cátedra de Minnesota, se interesaba en saber cómo veía yo, después del regreso a Cuba, mis experiencias de Princeton y cuáles eran mis futuros planes.

Apenas reincorporado a su cátedra, una carta mía le llevó la más triste noticia que podía esperar: la de la súbita muerte de Francisco José Castellanos, en quien había cifrado sus mayores esperanzas. Me decía: "Yo no sé si usted mismo se da cuenta de lo que significa para mí lo ocurrido: perder un amigo como Francisco José es perder una de las razones de existir". Se lamentaba de que dejándose vencer por el exceso de ocupaciones, no le hubiera escrito más a menudo, y concluía: "No puedo hablarle largamente de él: no me es fácil dominarme".

Terminado su curso, Pedro Henríquez Ureña se despide definitivamente de Minnesota. Lo llamaban de México, donde había sido designado Secretario de Educación José Vasconcelos, una de las figuras de formación cercana a él durante su anterior estancia, cuando en el Ateneo de la Juventud se forjaban los nuevos hombres que habrían de dar explendor a las letras y al pensamiento mexicano. Junto a Vasconcelos participa en la cruzada en pro de la afirmación de la cultura, que se intensifica a la vez que la otra encaminada a combatir el analfabetismo. De allá me llegó, recién instalado, la invi- 
tación a trabajar en el gran empeño. Como Director del Departamento de Intercambio Universitario, confeccionó los planes de la colección de clásicos, y estuvo empeñado en recoger el material necesario para una Antología Hispano Americana que la Universidad se proponía editar. Sus cartas ahora son apremiantes en la solicitud de obras cubanas, principalmente de Martí y de Casal. Pero no olvida a otro de sus amigos de 1914, a Luis A. Baralt, en quien piensa como posible profesor al crearse la Escuela de Verano en la Universidad de México, de la que fue principal animador y organizador. Las peticiones de libros y de datos sobre nuestros poetas y escritores se suceden. En una carta dice: "Mucho querría escribirle de otras cosas, pero mi cabeza no puede pensar sino en cosas concretas : efectos de la labor". Era el gran momento de efervescencia de los planes de Vasconcelos, en los que trabajaba sin descanso en infinidad de proyectos que pasaban inmediatamente a convertirse en realidades. $Y$ junto a él estaban los jóvencs que ya eran la promesa: Daniel Cosío Villegas y Eduardo Villaseñor, de quienes me hablaba con frecuencia. En manos de Daniel Cosío, a quien llama "mi grande y nuevo amigo", deja las pruebas de su libro $M i$ España, que acaba de entregar a la imprenta cuando en julio de 1921 emprende viaje a América del Sur, formando parte de una misión enviada por México. Y de Cosío y de Villaseñor me envía trabajos para publicar en nuestras revistas, especialmente en El Fígaro, concretando así su juicio sobre ellos: "Son de los nuevos que más prometen".

Para no hacer excesivamente extensa esta evocación, omitimos interesantes detalles de su intervención en nuestro empeño de realizar, en colaboración con José Antonio Fernández de Castro, la antología de lo poesía moderna en Cuba. Conoció el plan, hizo sugestiones muy atinadas, nos ayudó en nuestro trabajo, ansioso de que se hicieran las cosas bien de una vez. Pero sí no queremos dejar de recoger sus indicaciones sobre Martí: "En mi opinión debe dedicarse a Martí el mayor espacio, pues cada día me parece Martí el mejor poeta de Cuba (y naturalmente el mejor prosista también)".

Sobre el estilo encuentro muchas notas interesantes en la relectura de su correspondencia. En una carta le había planteado distintos problemas, y uno de ellos trataba de los nuevos 
escritores españoles — de los que escribían hacia 1922-. En su respuesta Pedro Henríquez Ureña apuntaba: "Actualmente todo el mundo en España escribe de modo muy distinto de lo que se creía "estilo español". Ya nadie — sino algunos académicos que sólo publican en lugares que no se leen- escribe párrafos largos. Azorín y la lectura de los escritores franceses ha cambiado el estilo español. En Cuba sí subsiste el viejo estilo, pero le aseguro que aun en los diarios más conservadores, más reaccionarios de Madrid se escribe de modo moderno. La mentalidad de la España nueva, además, y no sólo el estilo, ha cambiado".

Sobre el uso de las palabras encuentro insistentes comentarios que son de utilidad divulgar. Siente el horror de las palabras que llama pedantes, - -y eso a propósito del término "estado anímico", que yo había usado en un escrito añadiendo que son palabras que hacen pesado el lenguaje. Y me ofrece su propia experiencia para establecer como regla a la que él mismo ha llegado, el usar el menor número de palabras no sólo pedantes, sino aún meramente técnicas, tratando de usar siempre las más sencillas y más claras, aun para hablar de las cosas más abstrusas. Y resumiendo su pensamiento acerca del estilo, dice en una carta:

En el estilo, el problema principal es el de la "unidad de tono", y eso es muy difícil de definir a priori. Esa unidad de tono la tiene Varona, la tenía Rodó, la tiene Valle-Inclán... Es aquello que el vulgo llama "ni una palabra de más ni una palabra de menos".

Vamos a terminar esta evocación con una referencia a su americanismo. Sabemos que Pedro Henríquez Ureña se formó en moldes clásicos, que en literatura española su erudición era pasmosa. Alfonso Reyes, conversando con Chacón y Calvo cuando ambos vivían en la misma casa de Pardiñas 32, en Madrid, le preguntaba una vez: ¿Crees tú, José María, que haya quien sepa más que Pedro? Pero el gran conocedor de las letras hispanas no desdeñó ocuparse de nuestra literatura americana, más aún, se empeñó en señalar la necesidad de una depuración de nuestra cultura, porque según su decir, sabíamos muchas cosas, pero no las sabíamos bien, y no atinábamos a 
distinguir entre las doctrinas serias y las disparatadas, entre las buenas y las malas fuentes. He aquí su gran labor: su constante lección hacia las mejores normas de nuestras letras. Un amigo que hacía dilucidaciones alrededor del americanismo y que incluía nombres indebidamente y omitía otros, le movió este comentario: "y cree que no soy americanista porque soy hispanista. Me temo que en Cuba, todavía, ser americanista, cubanista, digamos, implica ser antiespañol; y hay uno que otro país de América donde todavía se piensa así". Limpio de prejuicios, no veía peligros que a otros se le antojaban, y por el contrario, su simpatía por España no enturbiaba su límpido sentido americanista. "Tengo simpatía por España -me dice en una carta de 1923 - porque la veo luchar por lo mismo que nosotros, pueblo desdichado como México o el Perú, no feliz como la Argentina o el Uruguay". México acababa de sentir entonces una nueva amenaza con el levantamiento de Veracruz. Y él veía así el problema:

\footnotetext{
Ahora deben definirse las cosas: en México hay siempre dos orientaciones, que yo llamo peladistas y decentistas. Los peladistas son generalmente honrados; los decentistas son con frecuencia ladrones en diversas formas. Ahora el decentismo se ha levantado en Veracruz. Si triunfan, prolongarán las dificultades de México; si fracasan, México podrá continuar su programa.
}

Se inicia el año 1924. A pesar de haber vivido abrumado de trabajo, el problema económico no le deja escribir. Ahora, desde hace un año ha creado un hogar: su matrimonio con Isabel Lombardo Toledano, hermana de su discípulo Vicente, y el nacimiento de su hija, le dan una nueva responsabilidad a su vida. Sus palabras son una desolación: "no escribiré más mientras no tenga descanso económico". Su teoría estaba sintiéndola en su propio espíritu. $\mathrm{Y}$ determina por irse a Buenos Aires en busca de ese sosiego económico que necesitaba.

Tres meses después - junio de 1924- pasaba por La Habana. Natacha, su hija, venía en brazos. No transcurrió un solo día sin que le visitara, ayudándole en sus urgentes problemas. Al tomar el barco, me dijo adiós con estas palabras: “dialogaremos sobre el mar". En la Argentina vivió veintidós 
años. Allí, como antes en todas partes, se rodeó de afectos y realizó su más importante obra de creador y de guiador.

Aun tuvo una última oportunidad de visitar La Habana. Había sido invitado por la Universidad de Harvard, para ocupar la cátedra Charles Eliot Norton, en el curso académico 1940-1941. A su salida la intelectualidad argentina lo despidió con un acto al que concurrió todo lo más representativo del país, y que se efectuó en la Universidad Popular Alejandro Korn, testimoniándole "al escritor, al maestro y al amigo, la simpatía y solidaridad de los que en este país han apreciado su labor y gozado de su amistad". Francisco Romero dijo palabras de despedida al "buen americano", como acertó a calificarlo. Después de haber desempeñado brillantemente su cometido, pronunciando en inglés las lecciones que después constituyeron su obra son precedentes Literary Currents in Hispanic America, de regreso a Buenos Aires se demoró algunos días entre nosotros. Chacón y Calvo ocupaba la Dirección de Cultura del Ministerio de Educación, y había fundado el Instituto de Altos Estudios, inaugurado con un curso memorable del gran filólogo Karl Vossler. Pedro Henríquez Ureña ofreció desde la nueva cátedra algunas conferencias de las que habían sido objeto de sus lecciones en Harvard, y recordamos que escritas como estaban en inglés, las iba traduciendo al español, sin que el auditorio pudiera notarlo.

Días después tomaba el barco de regreso para Buenos Aires. Allá le esperaba el trabajo cada día creciente. Además de las cátedras en las Universidades de Buenos Aires y de La Plata, y de sus labores en el Instituto de Filología, que en unión de Amado Alonso regenteaba, debía dar forma definitiva a la edición de su nuevo libro completando sus notas innumerables, y a diario trabajar en las colecciones que había incorporado a la Editorial Losada, y que estaban a su cuidado por entero. Allá murió, cuando realizaba el último de sus viajes de Buenos Aires a La Plata, para dar su clase diaria.

Había tenido la esperanza de encontrar su amistad generosa de siempre en un viaje al que me había alentado, pues 
invitado por la Comisión Argentina de Cooperación Intelectual, por generosa distinción de su Secretario, Don Antonio Aita, mis conferencias se habían señalado para el mes de octubre de 1946. Un escueto cable de Buenos Aires, que algún periódico de La Habana recogió, nos trajo la noticia de su muerte, ocurrida el 12 de mayo de 1946. Sólo hallé el recuerdo imborrable de una vida íntegramente consagrada a las más puras dignidades del espíritu. $\mathrm{Y}$ tuve el alto honor de rendirle allí donde se guardaba con devoción el culto a su memoria, en la Cátedra Popular Alejandro Korn de la Universidad de La Plata, tan vinculada a su obra, de la que había sido uno de sus fundadores, mi humilde testimonio de devoción, al leer en aquel recinto mi trabajo "Pedro Henríquez Ureña, primado de la cultura americana".

FÉlix Lizaso, Archivo Nacional, La Habana, Cuba. 
